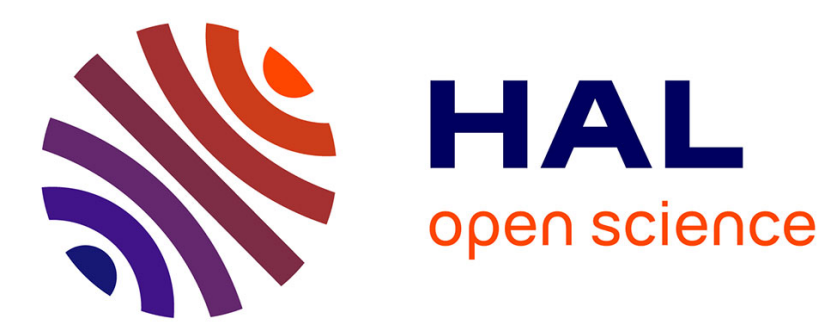

\title{
Longitudinal Executive Changes in Drivers with Parkinson's Disease: Study Using Neuropsychological and Driving Simulator Tasks
}

\author{
Maud Ranchet, Emmanuel Broussolle, Laurence Paire-Ficout
}

\section{To cite this version:}

Maud Ranchet, Emmanuel Broussolle, Laurence Paire-Ficout. Longitudinal Executive Changes in Drivers with Parkinson's Disease: Study Using Neuropsychological and Driving Simulator Tasks. European Neurology, 2016, 76 (3-4), pp.143-150. 10.1159/000448992 . hal-01366184v2

\section{HAL Id: hal-01366184 \\ https://hal.science/hal-01366184v2}

Submitted on 11 May 2017

HAL is a multi-disciplinary open access archive for the deposit and dissemination of scientific research documents, whether they are published or not. The documents may come from teaching and research institutions in France or abroad, or from public or private research centers.
L'archive ouverte pluridisciplinaire HAL, est destinée au dépôt et à la diffusion de documents scientifiques de niveau recherche, publiés ou non, émanant des établissements d'enseignement et de recherche français ou étrangers, des laboratoires publics ou privés. 
Longitudinal executive changes in drivers with Parkinson's disease:

\section{Study using neuropsychological and driving simulator tasks}

Maud Ranchet, $\mathrm{PhD}^{1^{*}}$, Emmanuel Broussolle ${ }^{2,3,4}, \mathrm{MD}, \mathrm{PhD}$, Laurence Paire-Ficout, $\mathrm{PhD}^{1}$

${ }^{1}$ IFSTTAR/LESCOT, Bron, France

${ }^{2}$ Université Lyon 1, Faculté de Médecine Lyon Sud Charles Mérieux

${ }^{3}$ Hospices Civils de Lyon, Hôpital Neurologique Pierre Wertheimer, Service de Neurologie C, Lyon, France

${ }^{4}$ CNRS, UMR 5229, Centre de Neurosciences Cognitives, Lyon, France

Running title: Changes in executive functions in PD drivers

\section{${ }^{*}$ Corresponding author:}

Maud Ranchet, IFSTTAR/LESCOT, 25 Avenue Francois Mitterrand, 69500 Bron

Tel: 706-446-3451; Email: mranchet@gmail.com; maud.ranchet@ifsttar.fr

Word count: 2995 words (Word limit: 3000 words)

Key words: Parkinson's Disease, Cognition, Neuropsychology, Safety, Longitudinal Study, Driving 


\section{Abstract}

Background/Aims: (1) To investigate how specific executive functions change over 2 years in drivers with Parkinson's Disease (PD) compared to controls, using both neuropsychological and driving simulator tasks; and (2) to explore the association between the decline of specific executive functions and changes in driving habits in PD.

Methods: Sixteen PD patients and 21 controls twice underwent neuropsychological testing and performed tasks on a driving simulator, at a distance of approximately 2 years. Questions on participants' self-perception of their driving ability were administered.

Results: A significant decline was observed in shift cost over time (Plus minus test) in patients $(p=0.008)$. This decline was greater in patients than in controls $(p=$ 0.008). No significant change emerged over time in the flexibility cost of PD patients on a simulator $(p=0.158)$. Significant correlations were found between the decline in shift cost over time and driving question outcomes $(p<0.05)$.

Conclusion: This study reveals a differential course of executive functions in PD. Over time, patients displayed a significant decline in flexibility, associated with modifications in their driving. Flexibility seems to be affected later than updating in the disease. This research opens new avenues in cognitive and driving rehabilitation.

Word count: 200 


\section{Introduction}

Parkinson's disease (PD) is a progressive neurodegenerative disorder which affects the instrumental activities of daily living, including the ability to drive a car [15]. The number of individuals with PD is expected to grow substantially over the next 20 years [6], posing challenges for health care professionals and driving rehabilitation specialists who determine fitness-to-drive.

Although the best-known deficits in PD are motor in nature, non-motor cognitive deficits may also appear, even in the early stages [7]. The most frequentlyreported of these early-stage cognitive deficits occur in the domains of executive function and memory [7].

While cross-sectional studies of patients at various stages of PD show cognitive changes $[7,8]$, few longitudinal studies have examined changes in cognitive function in PD $[9,10]$. Discrete cognitive decline has been shown to occur in PD, even over short-periods [9, 11]. Muslimovic et al. [11] showed that in newlydiagnosed PD patients, cognitive performance subsequently decreased over three years. The most severe deficit after three years affected measures of psychomotor speed and attention. Although deterioration in memory, visuospatial skills and executive function was of lesser magnitude, it was nevertheless more pronounced than in healthy controls. Findings from a previous study showed that executive function tasks proved most sensitive to disease progression [9].

Executive functions are paramount in most instrumental activities of daily living, including the ability to drive a car. In two recent studies, we showed the impact of specific executive functions on driving in individuals with PD [2, 4]. To date, only one prospective follow-up study has investigated driving abilities and crash risk in 
individuals with PD [12]. This research showed that 2 years after baseline, the risk of driving cessation was higher in PD drivers than in controls. Cognitive and visual impairments and severity of parkinsonism were associated with driving cessation in the PD group.

To our knowledge, no study has investigated the decline of specific executive functions over time in individuals with PD who continue to drive. Previously, we described the demographic, clinical and driving characteristics of 25 individuals with mild-to-moderate PD and 25 controls who were active drivers [4]. Our experimental approach consisted of isolating executive functions in a driving context. Participants performed an executive task while driving a simulator. Baseline findings (t0) revealed an updating impairment in drivers with PD in both neuropsychological tests and the simulator task. We now present the 2-year follow-up (t2) in individuals with PD and controls who are still active drivers.

The aims of this study were (1) to investigate how specific executive functions change over 2 years in individuals with PD compared to controls and (2) to explore the associations between the decline of specific executive functions and changes in driving in individuals with PD.

\section{Materials and Methods}

\section{$\underline{\text { Participants }}$}

At the initial session (t0), 25 individuals with PD (mean age: $65.4 \pm 5.2$ ) and 25 healthy controls (mean age: $66.7 \pm 4.4$ ) matched for sex, age, education level and driving experience were included [4]. At the second session (two years later, t2), 16 of the 25 individuals with PD were reassessed after an average follow-up of $821 \pm$ 92.89 days (Table 1). Five individuals with PD refused retesting, 3 stopped driving 
and one could not be retested due to dementia or severe confusion. Twenty-one of the 25 controls were reassessed after an average follow-up of $779 \pm 61.37$ days. Four controls refused retesting. No significant differences in demographic and clinical variables appeared at t0 between the individuals with PD who declined retesting and those who agreed to participate in the second session $(p>0.05)$. Similar results were found in controls. The average follow-up period for patients was not significantly different from the follow-up period of controls.

Disease progression was significantly more advanced in PD patients at t2 than at t0 (Hoehn and Yahr score: $1.75 \pm 0.32$ at t0 versus $2.22 \pm 0.41$ at $t 2, p=0.002$ ). Daily levodopa dosages were significantly higher in PD patients at t2 than at t0 (Levodopa dosage (mg): $270.31 \pm 223.46$ at t0 versus $464.29 \pm 441.66$ at $\mathrm{t} 2, \mathrm{p}=0.002)$.

Fourteen individuals with PD were treated with levodopa. Nine individuals with PD were taking dopamine agonists (pramipexole, ropinirole, piribedil), 3 were on COMT inhibitors (entacapone), and 5 on MAO inhibitors (selegiline, rasagiline). One patient was medication-free.

\section{Inclusion criteria}

Inclusion criteria for patients were as follows: mild-to-moderate-stage PD; idiopathic PD in accordance with the United Kingdom's Parkinson's Disease Brain Bank criteria [13]; older people with no neurological disease (control group); current regular drivers using a car with a manual gearbox.

\section{Exclusion criteria}

Exclusion criteria included: cessation of driving; global cognitive deterioration, based on a score of 24 or less in the Mini Mental State Examination (MMSE); moderate-tosevere depression based on a clinical interview and a score of 17 or more in the 
Beck Depression Inventory; far visual acuity inferior to 6/10; presence of neurological disorders other than idiopathic PD.

The study was approved by the local biomedical ethics committee. Informed written consent was obtained from all subjects following the Helsinki guidelines.

\section{Neuropsychological assessment}

The same methodology was used at t0 and t2 (for more details, see explanations in Ranchet et al. [4]). Psychomotor speed was measured using part A of the TMT.

Global executive function was assessed by the Trail Making Test (TMT B-A) and individual executive functions such as mental flexibility, updating and inhibition were assessed by the Plus Minus Task (PMT) (shift cost), n-back task (Response times in 2-back condition), and Stroop test (inhibition cost), respectively.

\section{Driving simulator and experimental tasks}

The experiment was conducted using a fixed-base simulator, a Renault Espace car with a manual gearbox and hidden instrumentation and sensors. The vehicle has a three-screen front view with a horizontal visual field of 150 degrees and a vertical visual field of 40 degrees. Participants familiarized themselves with simulated driving for 20 minutes. The tasks were performed by using in-house software developed at IFSTTAR. The refresh rate was $30 \mathrm{~Hz}$. In the updating task, the main task was to recall the three last-seen road signs while driving. In the flexibility task, participants were instructed to switch between two tasks and indicate the colour of the road sign when it was placed on the left-hand side or its shape when it was placed on the right-hand side [for a detailed description, see 4]. In both tasks, participants were asked to drive at a constant speed of $90 \mathrm{~km} / \mathrm{h}$ in 
both tasks. Task performances during simulated driving, mean speed and speed variability (mean SD of speed) were measured.

\section{Questions on self-perception of subjects' driving ability}

Participants replied to 3 questions about their habits and difficulties while driving. The first question was asked at t 0 and $\mathrm{t} 2$ and the last two were asked only at $\mathrm{t} 2$. Question 1 was: "How do you judge your driving skills?" with self-evaluation ranging from 0 to 10 . Questions 2 and 3 were adapted from a commonly-used questionnaire [14]. Question 2 was: "Which driving situations are more difficult than two years ago?" Participants had to indicate which situations from the 17 propositions (e.g. highway driving, night driving) they found more difficult. The total number of difficult situations represented the difficulty score (/17). Question 3 was: "Which driving situations do you avoid?" The same situations as in Question 2 were proposed. The total number of avoided situations represented the avoidance score $(/ 17)$.

\section{Procedure}

Neuropsychological tests and tasks on the driving simulator were performed at the French institute of science and technology for transport, development and network (IFSTTAR) in France at t0 and t2. Each session lasted 3 hours. All patients were tested during "on" medication periods. The same neuropsychological tests and driving simulator tasks were administered at to and t2. The same investigator (MR) assessed all participants at both sessions.

Statistical analysis 
Variables were assessed for normality using Shapiro-Wilk tests. Differences across time were examined using two-tailed Wilcoxon Ranked Sums tests to investigate the change over time in both groups [9]. Change scores were calculated as the score at follow-up (t2) minus the score at baseline (t0) in order to explore the extent to which a function declined over time [15]. Differences between patients and controls at baseline (t0), at follow-up (t2) and change scores were analyzed with a one-way independent sample t test or a U Mann-Whitney test, where appropriate. We used a two-tailed t-test, U Mann-Whitney test or Fisher exact test for categorical variables on questionnaire data. Spearman correlations between the flexibility change score and data from the questionnaire were analyzed in order to investigate whether the significant decline over time of specific executive functions was associated with a change in driving habits. A p-value of 0.01 was selected for both within-group and between-group comparisons due to the number of tests administered and the small sample size in the two groups. P-values $<0.05$ were significant for correlation analyses. Statistical analysis was carried out using SPSS 17.0.

\section{Results}




\section{Neuropsychological performances}

Between-group differences at t0 and t2

As expected, PD patients had lower MMSE scores than controls at t2. At t2, patients' response times were significantly longer than controls' response times in inhibition cost whereas at t0, no significant differences were observed between the two groups (Table 2).

Within-group differences - Decline over time

PD patients' performance remained stable over time on most tests. However, patients were significantly slower than controls when performing part A of the TMT. Importantly, shift cost declined significantly over time in patients, suggesting a decline in flexibility over time.

Controls' response times declined significantly over time in the 2-back condition, suggesting a decline in updating over time.

Change score - Magnitude of decline

The change score (right column in table 2) was used to assess the magnitude of decline in patients and controls. Change scores for part A of the TMT, and change scores for inhibition cost were significantly more pronounced in patients than in controls. The most relevant findings concerned the change score in shift cost, which was more pronounced in PD patients than in controls. Greater variability of performance was observed in PD patients than in controls.

To summarize, findings showed a significant decline in shift cost over time, and this was more pronounced in patients than in controls. 


\section{Driving simulator performances}

Between-group differences at t0 and t2

At $\mathrm{t} 2$, patients performed significantly more poorly than controls in the updating task (Table 3).

Within-group differences - Decline over time

Speed variability in the flexibility task was significantly higher at t2 than at t0 in patients.

Change score - Magnitude of decline

The average change score for flexibility cost was more pronounced in patients than in controls. However, the difference between the two groups did not reach statistical significance.

The two main findings reveal a significant deficit in patients' updating score on the simulator at $\mathrm{t} 2$, and a significant decline over time in their speed variability in the flexibility task on the simulator. 


\section{Questions on driving ability and self-perception}

\section{Question 1}

At t0, there was no difference between patients' and controls' judgment of their own driving competency. However, at t2, a significant difference concerning driving competence appeared between PD patients and controls (Table 4). Controls judged themselves significantly better at $\mathrm{t} 2$ than at $\mathrm{t} 0$.

\section{Question 2}

At t2, PD patients reported a greater number of difficult driving situations (from the 17 propositions) than controls, $\left(n_{\text {patients }}=3.94 \pm 3.21\right.$ vs $n_{\text {controls }}=1.62 \pm 1.53, U=242$, $\mathrm{p}=0.023)$.

\section{Question 3}

Patients also reported avoiding more driving situations than controls $\left(\mathrm{n}_{\text {patients }}=5.06 \pm 2.91\right.$ vs $\left.\mathrm{n}_{\text {controls }}=1.76 \pm 1.55, \mathrm{U}=284.5, \mathrm{p}<0.001\right)$.

\section{Correlations between the change score of shift cost (PMT) and driving question}

\section{$\underline{\text { scores in PD patients }}$}

Results showed a significant correlation between the change score of shift cost and the number of difficult driving situations at $\mathrm{t} 2(\mathrm{rho}=0.527, \mathrm{p}=0.043)$, and a significant correlation between the change score of shift cost and the number of avoided situations at $\mathrm{t} 2(\mathrm{rho}=0.543, \mathrm{p}=0.036)$.

In summary, patients reported a higher number of difficult driving situations, and avoidance of more driving situations than controls.

\section{Discussion}


Our findings show that in PD, cognitive decline is relatively slow over two years $[9,11,16]$. The decline over time occurs mainly on measures of psychomotor speed (TMT-part A), and this is consistent with previous results [11]. We will now discuss the main findings from our neuropsychological tests, driving simulator results and responses to driving questions.

\section{Neuropsychological tests show flexibility decline in PD}

We showed a significant decline in our PD patients' flexibility function over two years. The decline over time was significantly greater in PD drivers than in controls. Although findings from cross-sectional studies show a flexibility deficit in PD patients $[17,18]$, the decline in mental flexibility over two years of PD has not yet been specifically investigated. By contrast, we found no significant decline in mental flexibility over time in controls. It is possible that in normal ageing, the flexibility deficit appears later $[19,20]$. The present research suggests that the decline of mental flexibility over time is more sensitive to PD progression than to the progression of normal ageing.

While we did not find a significant decline over time for the updating function in drivers with PD in the 2 back condition, we did observe an updating deficit at t0 in the whole sample $(n=25)[4]$. At t2, no significant updating deficit was observed in patients compared to controls. Several explanations can be put forward to explain this absence of difference. Firstly, a deficit in the updating function might occur earlier in the progression of PD. Secondly, cognitive impairment may have been more severe in the patients who gave up. As the remaining patients were healthier, the difference between patients and controls with preserved global cognitive abilities (mean MMSE score at $t 2=29$ ) was not significant. Thirdly, the updating deficit in 
older adults may also be related to healthy age-related decline. This is consistent with studies that show an updating deficit in healthy older individuals whose average age is $70[19,21,22]$.

\section{Driving simulator tasks reveal a decrease in flexibility task performance}

Contrary to our observations in the neuropsychological tests, we did not see any significant decline over time in flexibility cost during driving in individuals with PD. However, a significant decline over time in speed variability was observed in patients during the flexibility task, and suggests poorer driving performances at t2 than at t0. It is possible that the drivers with PD allocated attentional resources to the flexibility task instead of maintaining a stable driving speed. Previous studies have shown that people with PD have difficulty completing two tasks simultaneously [23]. Findings at t2 also showed that drivers with PD had poorer performances in the updating task than controls. This result was not observed in the n-back task. The appearance of the updating deficit during simulator driving may be due to an increase in cognitive demand.

\section{PD patients have appropriate self-perception of their driving ability}

A large proportion of individuals with PD self-regulated their driving habits over two years, reducing the number of miles driven per year. At 2 , they reported a greater number of difficult situations and avoided more driving situations than controls. These results are in accordance with those described in the literature $[24,25]$. At t0, we did not find a significant difference between the two groups' self-assessment of their driving skills. Nor did we show a significant change in their self-assessment of driving skills over a two-year disease-period. Cognitive decline may be too discrete to interfere with self-perception of their driving abilities. While patients' perception of their driving skills remained stable over two years of progression, we observed that 
controls judged themselves significantly better at $\mathrm{t} 2$ than $\mathrm{t} 0$. This perceived improvement may stem from a time-related decline in controls' self-evaluation ability. This finding could be related to a decline over time in controls' perception of their driving skills. Older controls had difficulty estimating their driving abilities accurately [26]. Future studies on a larger-sized sample should explore changes perceived over time in patients and controls.

Significant correlations between the change score in shift cost and driving question outcomes suggest that the decline in flexibility over two years of PD was associated with a change in patients' driving habits. We assume that the decline in flexibility over two years of PD may already affect driving. Previous cross-sectional studies have shown that flexibility may impact driving performance $[2,27]$. Further research should continue to explore the effect of cognitive tasks on driving performance in the real world.

\section{Limitations of the study}

The small sample size limits the use of statistical methods applied to longitudinal studies [16]. We cannot therefore generalize these findings to the general PD population. The absence of significant changes between the two assessments could be due to the fact that heterogeneity in the progression of PD is greater than that of normal ageing $[16,28]$. The fact that performances during simulated driving remained relatively stable or improved could reflect practice effects. It has been demonstrated that performance of relatively difficult or novel tasks tends to improve due to increased familiarity with the procedures [29]. Other driving measures sensitive to vehicle control such as lane position and variation of lane position should be further 
explored. The use of driving simulators in longitudinal studies needs to be further explored.

A limitation is the small sample size that limits the use of statistical methods applied to longitudinal studies and the generalization to the PD population. The lack of significant changes over time could be due to a greater heterogeneity in the

progression of PD. ${ }^{14}$ Performances on the driving simulator remained relatively stable or improved, which could reflect practice effects. The use of driving simulators in longitudinal studies needs to be further explored.

\section{Perspectives}

This study's findings may have implications for future research in cognitive and driving rehabilitation. Targeted training of specific executive functions could prove to be a key component in cognitive rehabilitation interventions aimed at improving driving abilities and driving-related cognitive functions in patients with PD [30]. In the early stages of PD, training of the updating function may be more beneficial than specific training of the flexibility function. However, later in the disease, specific training of the flexibility function might improve driving abilities and cognitive functions. Further research should explore the potential of a non-contextual training program to improve cognitive functions and mobility in patients with PD.

\section{Conclusion}

This research showed a differential course of executive functions across PD, leading to modifications in driving habits. Updating information in the working memory appears to be affected earlier in the disease than flexibility [4]. Decline in flexibility 
appears to be more pronounced in patients than in controls, suggesting that, over two years of progression, flexibility is more sensitive to PD than to normal ageing. Further longitudinal studies investigating the decline in cognitive functions over time in drivers with PD should be considered.

\section{Acknowledgements}

The authors thank M-F Boyer for her contribution to the inclusion of all participants. Many thanks are also due to participants of the study. MR was the recipient of a fellowship from the Ministere de la recherche. This work was supported by Fondation Neurodis-Fondation Partenariale Lyon 1 and the French institute of science and technology for transport, development and network (IFSTTAR).

\section{Conflict of interest}

The authors have no conflict of interest to report. 


\section{References}

[1] Devos H, Vandenberghe W, Tant M, Akinwuntan AE, De Weerdt W, Nieuwboer A, Uc EY Driving and off-road impairments underlying failure on road testing in Parkinson's disease. Mov Disord 2013;28: 1949-1956.

[2] Ranchet M, Paire-Ficout L, Uc EY, Bonnard A, Sornette D, Broussolle E Impact of specific executive functions on driving performance in people with Parkinson's disease. Mov Disord 2013;28: 1941-1948.

[3] Uc EY, Rizzo M, Johnson AM, Dastrup E, Anderson SW, Dawson JD Road safety in drivers with Parkinson disease. Neurology 2009;73: 2112-2119.

[4] Ranchet M, Paire-Ficout L, Marin-Lamellet C, Laurent B, Broussolle E Impaired updating ability in drivers with Parkinson's disease. J Neurol Neurosur Psychiatry 2011;82: 218-223.

[5] Ranchet M, Broussolle E, Poisson A, Paire-Ficout L Relationships between cognitive functions and driving behavior in Parkinson's disease. Eur Neurol 2012;68: 98-107.

[6] Dorsey ER, Constantinescu R, Thompson JP, Biglan KM, Holloway RG, Kierburtz K, Marshall FJ, Ravina BM, Schifitto G, Siderowf A, Tanner CM Projected number of people with Parkinson disease in the most populous nations, 2005 through 2030. Neurology 2007;68: 384-386.

[7] Muslimovic D, Post B, Speelman JD, Schmand B Cognitive profile of patients with newly diagnosed Parkinson disease. Neurology 2005;65: 1239-1245.

[8] Owen AM, Iddon JL, Hodges JR, Summers BA, Robbins TW Spatial and nonspatial working memory at different stages of Parkinson's disease.

Neuropsychol. 1997;35: 519-532. 
[9] Azuma T, Cruz R, Bayles KA, Tomoeda CK, Montgomery EB A longitudinal study of neuropsychological change in individuals with Parkinson's disease. Int J Geriatr Psychiatr 2003;18: 1043-1049.

[10] McLay P The Parkinsonian and driving. Rehabilitation Scene 1989;11: 50-51.

[11] Muslimovic D, Post B, Speelman JD, De Haan R, Schmand B Cognitive decline in Parkinson's disease: A prospective longitudinal study. J Intern Neuropsychol Soc 2009;15: 426-437.

[12] Uc EY, Rizzo M, Johnson AM, Emerson JL, Liu D, Mills ED, Anderson SW, Dawson JD Real-life driving outcomes in Parkinson disease. Neurology 2011;76: 1894-1902.

[13] Gibb WR, Lees AJ The significance of the Lewy body in the diagnosis of idiopathic Parkinson's disease. Neuropathol. and Applied Neurobiol. 1989;15: 27-44.

[14] De Raedt R, Ponjaert-Kristoffersen I Can strategic and tactical compensation reduce crash risk in older drivers? Age and Ageing 2000;29: 517-521.

[15] Schmand B, de Bie RMA, Koning-Haanstra, de Smet JS, Speelman JD, van Zomeren AH Unilateral pallidotomy in PD: A controlled study of cognitive and behavioral effects. Neurology 2000;54: 1058-1064.

[16] Tröster Al, Woods SP, Morgan EE Assessing cognitive change in Parkinson's disease: Development of practice effect-corrected reliable change indices. Arch. Clin. Neuropsychol. 2007;22: 711-718.

[17] Kehagia AA, Cools R, Barker RA, Robbins TW Switching between abstract rules reflects disease severity but not dopaminergic status in Parkinson's disease. Neuropsychol. 2009;47: 1117-1127. 
[18] Cools R, Barker RA, Sahakian BJ, Robbins TW Mechanisms of cognitive set flexibility in Parkinson's disease. Brain 2001;124: 2503-2512.

[19] Etienne V (2008) in Lyon University of Lyon.

[20] Sorel O, Pennequin V Aging of the Planning process: The role of executive functioning. Brain and Cognition 2008;66: 196-201.

[21] Hartman M, Dumas J, Nielsen C Age Differences in Updating Working Memory: Evidence from the Delayed-Matching-To-Sample-Test. Aging Neuropsychol. Cogn. 2001: 14-35.

[22] Van der Linden M, Brédart S, Beerten A Age-related differences in updating working memory. British Journal of Psychology 1994;85: 145-152.

[23] Uc EY, Rizzo M, Anderson SN, Sparks JD, Rodnitzky RL, Dawson JD Driving with distraction in Parkinson disease. Neurology 2006;67: 1774-1780.

[24] Crizzle AM, Myers AM, Almeida QJ Self-regulatory practices of drivers with Parkinson's disease: Accuracy of patient reports. Parkinsonism Relat. Disord. 2013;19: 176-180.

[25] Crizzle AM, Myers AM Examination of naturalistic driving practices in drivers with Parkinson's disease compared to age and gender-matched controls. Accid Anal Prev 2013;50: 724-731.

[26] Blanchard RA, Myers AM, Porter MM Correspondence between self-reported and objective measures of driving exposure and patterns in older drivers. Accid Anal Prev 2010;42: 523-529.

[27] Adrian J, Postal V, Moessinger M, Rascle N, Charles A Personality traits and executive functions related to on-road driving performance among older drivers. Accid Anal Prev 2011;43: 1652-1659. 
[28] Aarsland D, Andersen K, Larsen JP, Perry R, Wentzel-Larsen T, Lolk A, Kragh-Sorensen $\mathrm{P}$ The rate of cognitive decline in Parkinson disease. Arch Neurol 2004;61: 1906-1911.

[29] Lezak MD (1995) Neuropsychological Assessment, Oxford University Press, New York.

[30] Devos H, Ranchet M, Akinwuntan AE, Uc EY Establishing an evidence-base framework for driving rehabilitation in Parkinson's Disease: A systematic review of on-road driving studies. Neurorehabilitation 2015;37: 35-52. 
Table 1. Demographic and clinical characteristics of PD patients and controls at t2

\begin{tabular}{llll}
\hline & PD group & Control group & \\
& $\mathrm{n}=16$ & $\mathrm{n}=21$ & $p$-value* \\
& mean (SD) & mean (SD) & two-tailed \\
\hline Age (years) & $67.8(4.8)$ & $69.1(3.9)$ & 0.380 \\
Sex, $\mathrm{n}$ men (\%) & $12(75)$ & $17(81.0)$ & 0.705 \\
Years of education & $13.5(3.3)$ & $13.6(2.7)$ & 0.938 \\
Years of driving & $43.4(5.1)$ & $45.1(6.0)$ & 0.348 \\
Mileage driven per year ${ }^{\mathrm{a}}, \mathrm{n}$ & $6 / 3 / 6 / 1$ & $0 / 4 / 16 / 1$ & $\mathbf{0 . 0 0 6}$ \\
BDI score 21 items & $9.6(4.7)$ & $5.3(3.0)$ & $\mathbf{0 . 0 0 9}$ \\
ESS score (max. score: 24$)$ & $9.1(2.8)$ & $6.0(3.3)$ & $\mathbf{0 . 0 1}$ \\
Hoehn and Yahr stage (range: 0-5) & $2.2(0.4)$ & - & \\
Disease duration (years) & $6.9(4.3)$ & - & \\
Disease onset age (years) & $60.8(7.1)$ & - & \\
UPDRS - motor score (max.score: 108$)$ & $17.0(4.4)$ & - & \\
Levodopa dosage (mg/day) & $464.3(141.7)$ & - & \\
\hline
\end{tabular}

Values in bold are significant.

Abbreviations: BDI: Beck Depression Inventory; ESS: Epworth Sleepiness Scale; UPDRS: Unified Parkinson Disease Rating Scale

${ }^{*}$ P-value $<0.05$

${ }^{a}$ Less than $3000 \mathrm{~km} /$ between 3500 and $7000 \mathrm{~km} /$ between 7000 and $20000 \mathrm{~km} /$ more than $20000 \mathrm{~km}$

${ }^{\mathrm{b}}$ Levodopa (+dopa-decarboxylase inhibitor) without dopaminergic agonists 
Table 2. Baseline, follow-up, and change scores in neuropsychological tests for PD patients and elderly controls.

\begin{tabular}{|c|c|c|c|c|c|}
\hline & & to & t2 & & Change score $^{c}$ \\
\hline & n Group & mean (SD) & mean (SD) & $\begin{array}{l}p- \\
\text { value }^{a}\end{array}$ & mean SD) \\
\hline Global cognitive assessment & & & & & \\
\hline MMSE & 16 patients & $28.1(1.2)$ & $27.6(1.5)$ & 0.286 & $-0.5(1.6)$ \\
\hline & 21 controls & $29.2(0.8)$ & $29.3(0.7)$ & 0.564 & $0.05(0.8)$ \\
\hline$p$-value ${ }^{\mathrm{b}}$ & & 0.002 & 0.001 & & 0.083 \\
\hline Trail Making Test (TMT) & & & & & \\
\hline Part A times (s) (1) & 15 patients & $41.8(10.8)$ & $50.8(13.1)$ & 0.007 & $9.0(10.4)$ \\
\hline & 21 controls & $44.3(16.8)$ & $39.1(15.4)$ & 0.217 & $-5.2(18.8)$ \\
\hline$p$-value & & 0.455 & 0.010 & & 0.008 \\
\hline Part B times (s) (2) & 15 patients & $79.3(36.2)$ & $113.5(83.9)$ & 0.041 & $34.3(58.3)$ \\
\hline & 21 controls & $75.4(27.8)$ & $75.5(25.5)$ & 0.852 & $0.1(22.8)$ \\
\hline & & 0.424 & 0.121 & & 0.048 \\
\hline $\operatorname{TMT}(B-A)(2)-(1)$ & 15 patients & $37.5(29.4)$ & $62.7(76.9)$ & 0.348 & $25.3(58.8)$ \\
\hline & 21 controls & $31.1(19.6)$ & $36.4(21.5)$ & 0.348 & $5.3(24.5)$ \\
\hline$p$-value & & 0.392 & 0.424 & & 0.418 \\
\hline Stroop test - inhibition cost (s) & 14 patients & $63.4(30.5)$ & $85.6(61.2)$ & 0.014 & $22.1(47.2)$ \\
\hline & 21 controls & $53.5(19.4)$ & $53.9(16.3)$ & 0.602 & $0.4(12.9)$ \\
\hline$p$-value & & 0.209 & 0.007 & & 0.009 \\
\hline Updating & & & & & \\
\hline $\begin{array}{l}\text { n-back task } \\
\text { 2-back }\end{array}$ & & & & & \\
\hline Response times (ms) & 16 patients & $712.1(158.9)$ & $765.7(197.8)$ & 0.281 & $53.7(184.1)$ \\
\hline & 21 controls & $633.1(144.7)$ & $705.8(114.4)$ & 0.006 & $72.7(99.8)$ \\
\hline$p$-value & & 0.122 & 0.145 & & 0.345 \\
\hline Errors & 16 patients & $2.8(2.4)$ & $4.4(3.5)$ & 0.083 & $1.7(3.1)$ \\
\hline & 21 controls & $1.5(2.3)$ & $2.1(2.9)$ & 0.240 & $0.7(2.4)$ \\
\hline$p$-value & & 0.009 & 0.018 & & 0.135 \\
\hline Flexibility & & & & & \\
\hline Plus Minus task - Shift cost & 15 patients & $17.8(13.4)$ & $31.9(27.8)$ & 0.008 & $14.2(21.1)$ \\
\hline & 21 controls & $20.4(12.8)$ & $20.7(15.7)$ & 0.641 & $0.3(15.3)$ \\
\hline$p$-value & & 0.255 & 0.140 & & 0.008 \\
\hline Information-processing speed & & & & & \\
\hline Stroop test - Color naming & 14 patients & 64.0. (10.8) & $68.1(14.8)$ & 0.046 & $4.1(6.7)$ \\
\hline & 21 controls & $62.5(7.4)$ & $64.3(10.0)$ & 0.303 & $1.8(5.9)$ \\
\hline$p$-value & & 0.420 & 0.301 & & 0.18 \\
\hline
\end{tabular}

Values in bold are significant $(p<0.01)$.

Abbreviations: MMSE: Mini Mental State Examination; SD: Standard Deviation; TMT: Trail Making

Test

${ }^{\text {a }} \mathrm{P}$-value for within-group comparisons (decline over time)

${ }^{\mathrm{b}} \mathrm{P}$-value for between-group comparisons (deficit)

${ }^{\mathrm{C}}$ Change score (magnitude of decline) $=$ score $\mathrm{t} 2$ - score t0. Positive values means poorer performances at $\mathrm{t} 2$. Negative values means better performances at $\mathrm{t} 2$. 
${ }^{\mathrm{d}}$ Inhibition cost was calculated as being the difference between mean completion times of the third condition and the mean completion times from the first two conditions.

${ }^{e}$ Shift cost was calculated as being the difference between mean completion times of the third list and mean completion times from the first two lists. 
Table 3. Baseline, follow-up, and change scores in driving simulator tasks for PD patients and elderly controls.

\begin{tabular}{|c|c|c|c|c|c|c|}
\hline & $\mathrm{n}$ & Group & $\begin{array}{l}\text { t0 } \\
\text { mean }(S D)\end{array}$ & $\begin{array}{l}\text { t2 } \\
\text { mean (SD) }\end{array}$ & $p$-value ${ }^{a}$ & $\begin{array}{l}\text { Change score }^{\mathrm{c}} \\
\text { mean (SD) }\end{array}$ \\
\hline \multicolumn{7}{|l|}{ Updating task } \\
\hline \multirow[t]{2}{*}{ Updating score, $\mathrm{n}$} & 15 & patients & $39.5(7.2)$ & $35.0(10.4)$ & 0.151 & $-4.5(10.3)$ \\
\hline & 20 & controls & $43.0(4.4)$ & $43.8(4.5)$ & 0.348 & $0.8(4.1)$ \\
\hline$p$-value ${ }^{b}$ & & & 0.078 & 0.003 & & 0.051 \\
\hline \multirow[t]{2}{*}{ Mean speed $(\mathrm{km} / \mathrm{h})$} & 15 & patients & $81.1(9.6)$ & $85.0(17.1)$ & 0.256 & $4.0(14.8)$ \\
\hline & 20 & controls & $82.9(6.3)$ & $81.0(8.76)$ & 0.313 & $-1.9(8.7)$ \\
\hline$p$-value & & & 0.193 & 0.408 & & 0.062 \\
\hline \multirow[t]{2}{*}{ Speed variability ${ }^{d}$} & 15 & patients & $8.6(3.1)$ & $11.4(4.9)$ & 0.088 & $2.8(5.1)$ \\
\hline & 20 & controls & $9.7(2.5)$ & $9.5(2.3)$ & 0.911 & $-0.2(3.1)$ \\
\hline$p$-value & & & 0.103 & 0.222 & & 0.033 \\
\hline \multicolumn{7}{|l|}{ Flexibiity task } \\
\hline \multirow[t]{2}{*}{ Flexibility cost } & 14 & patients & $61.8(556.9)$ & $497.4(543.0)$ & 0.158 & $435.6(970.0)$ \\
\hline & 20 & controls & $138.2(484.9)$ & $202.4(336.2)$ & 0.911 & $64.1(506.2)$ \\
\hline$p$-value & & & 0.472 & 0.058 & & 0.147 \\
\hline \multirow[t]{2}{*}{ Mean speed $(\mathrm{km} / \mathrm{h})$} & 14 & patients & $97.4(18.2)$ & $92.9(23.7)$ & 0.826 & $-4.4(30.6)$ \\
\hline & 20 & controls & $92.3(4.5)$ & $91.3(15.5)$ & 0.654 & $-0.9(15.7)$ \\
\hline$p$-value & & & 0.164 & 0.242 & & 0.376 \\
\hline \multirow[t]{2}{*}{ Speed variability } & 14 & patients & $4.3(1.9)$ & $11.7(9.8)$ & 0.006 & $7.4(9.9)$ \\
\hline & 20 & controls & $4.6(2.2)$ & $9.8(10.2)$ & 0.191 & $5.1(10.3)$ \\
\hline$p$-value & & & 0.383 & 0.071 & & 0.076 \\
\hline
\end{tabular}

Values in bold are significant $(p<0.01)$.

${ }^{a} \mathrm{P}$-value for within-group comparisons (differences across time)

${ }^{\mathrm{b}} \mathrm{P}$-value for between-group comparisons

${ }^{c}$ Change score (magnitude of decline) = score $\mathrm{t} 2$ - score t0. Positive values mean poorer performances at $t 2$. Negative values mean better performances at $t 2$.

${ }^{\mathrm{d}}$ Mean standard deviation of speed 
Table 4. Self-assessment of driving competence in patients and controls (question 1)

\begin{tabular}{llllll}
\hline & $\mathrm{n}$ & & $\mathrm{t} 0$ & $\mathrm{t}$ & -value $^{\mathrm{a}}$ \\
\hline Mean mark /10 (SD) & 16 & patients & $7.5(1.3)$ & $7.2(1.0)$ & 0.451 \\
& 21 & controls & $7.9(1.1)$ & $8.2(1.0)$ & $\mathbf{0 . 0 3 9}$ \\
-value $^{\mathrm{b}}$ & & & 0.147 & $\mathbf{0 . 0 0 9}$ & \\
\hline
\end{tabular}

Values in bold are significant

${ }^{a} \mathrm{P}$-value for within-group comparisons (differences across time)

${ }^{\mathrm{b}} \mathrm{P}$-value for between-group comparisons 